\title{
Cryogenic Mechanical Properties of PP/MMT Polymer Nanocomposites
}

\author{
N. Manoharan and V. Selvakumar* \\ AMET University, Chennai-603112, India; vselvakumar75@yahoo.in
}

\begin{abstract}
This article addresses the effect of Na+-Montmorillonite (MMT) on cryogenic mechanical properties of polypropylene (PP). Polypropylene/Montmorillonite (PP/MMT) nanocomposites were prepared by using twin-screw extruder incorporating the polypropylene grafted maleic anhydride (PP-g-mA) as compatibilizer is used for better dispersion of nanoclay in the polymer matrix. The dispersion and exfoliation of MMT in the nanocomposites were observed using transmission electron microscopy (TEM) and X-ray diffraction(X-RD). Mechanical behaviors of PP/MMT nanocomposites at both room temperature (RT) and liquid nitrogen temperature (77 K) were investigated in terms of tensile, flexural and impact properties. The mechanical results showed that the tensile strength of PP/MMT nanocomposites at both RT and $77 \mathrm{~K}$ reached the maximum at the $5 \mathrm{wt}$. \% MMT content, increased by $3.1 \%$ and $13.2 \%$, respectively, as compared with those of pure PP sample. The notched impact strength at RT increased from $22.33 \mathrm{~J} / \mathrm{m}$ for the pure PP matrix to 36.53 $\mathrm{J} / \mathrm{m}$ for the nanocomposite with the $5 \mathrm{wt} \%$ MMT content. The fracture surfaces of neat PP and PP/MMT nanocomposites were examined using Scanning Electron Microscopy (SEM). Finally, the dependence of the storage modulus and loss modulus of the MMT content was examined by Dynamic Mechanical Analyzer (DMA) at cryogenic temperature.
\end{abstract}

Keywords: Cryogenic Temperature, Mechanical Properties, Nanocomposites, Polymer

\section{Introduction}

The mechanical and thermal properties of polymers and composite structures can be altered through the use of various kinds of fillers. The dimensions of these fillers typically fall on a macroscopic $(1 \mu \mathrm{m}-1 \mathrm{~nm})$ length scale. Fillers of this type increase the stiffness and heat distortion temperature of a polymer, primarily because the filler makes up a significant proportion of the total mass. However, macroscopic fillers usually cause decreases in strength, impact resistance, and process ability ${ }^{1-3}$. A new area of composites research has emerged in the last two decades that utilizes nanoparticle fillers to alter the properties of polymers. Definitive results have not yet been achieved, but trends show that when processed properly small amounts ( $\leq 5 \mathrm{wt}$. \%) of nanoparticle fillers can increase the modulus, strength, toughness, resistance to chemical attack, gas impermeability, resistance to thermal degradation, and dimensional stability of polymeric materials. However, the majority of this work has focused on neat thermoplastics and it is only recently that thermosets have begun to be examined as potential matrices for nanocomposites ${ }^{3-9}$. With the rapid development of the space industry and superconductive technologies, polymer matrix and their composites have also been widely used in these fields. Successful applications of these materials highly depend on their performances at extreme low temperature (such as liquid nitrogen and liquid helium temperature), particularly for reusable launch vehicles. Previous studies have shown that MMT can effectively improve properties of polymer matrix at room temperature (RT)9-16. It is expected that it may also improve these properties at cryogenic temperature. Generally speaking, cryogenic properties of polymer matrix can be significantly different from those at RT because of the effect of large thermal contraction. The property improvement of PP/MMT nanocomposites cannot be simply inferred from the 
results of the property improvement of PP/MMT nanocomposites obtained at RT. To ensure the safety of the applications of these materials at the cryogenic temperature, it is indispensable to study cryogenic mechanical properties of PP/MMT nanocomposites. To our best of knowledge, no work has been reported on the cryogenic mechanical properties of PP/MMT nanocomposites. Therefore, in this paper, $\mathrm{PP} / \mathrm{MMT}$ nanocomposites were prepared and their mechanical properties at both RT and $77 \mathrm{~K}$ were experimentally investigated and compared.

\section{Experimental}

\subsection{Materials}

The PP has grade of H110MA with density of $0.910 \mathrm{~g} /$ $\mathrm{cc}$ and melt flow index (MFI) of $11 \mathrm{~g} / 10 \mathrm{~min}$, purchased from reliance Ltd, India. The coupling agent PP-g-MA purchased from Exxon mobile India Pvt. Ltd, India, with the grade name Exxlor PO 1020, with MFI $125 \mathrm{gm} / 10 \mathrm{~min}$ with $0.75 \%$ of grafting. Nanoclay i.e. unmodified MMT having CEC $92.6 \mathrm{meq} / 100 \mathrm{~g}$, purchased from southern clay products Inc, USA.

\subsection{Preparation of PP/MMT Nanocomposites}

Melt mixing of PP, PP-g-MAH (10 wt. \%) and unmodified MMT of 1, 3, 5 and $7 \mathrm{wt}$ \% carried out in counter rotating twin screw extruder. Prior to melt mixing, the PP and the nanofillers were preheated in a vacuum oven at $60 \mathrm{oC}$ for a time of 6 hours. PP was fed into the twin screw extruder at the rate of $5 \mathrm{~kg} /$ hour and the nanofillers were introduced subsequently at the melting zone. The process of manufacturing of PP/MMT nanocomposites were carried out at a two screw speed of $150 \mathrm{rpm}$ and maintain the temperature difference of barrel in twin screw extruder were 160,170 and $180^{\circ} \mathrm{C}$ between feed zones to die zone, followed by granulation in a pelletizer and drying. These pellets were injection molded by using injection moulding machine. The manufacturing of test specimens of tensile, flexural and impact strength as per ASTMD by using injection moulding machine with clamping force $800 \mathrm{~K}$ fitted with dehumidifier at a temperature range of $195-220^{\circ} \mathrm{C}$.

\subsubsection{X-ray Diffraction}

\subsection{Characterization Methods}

Philips X'Pert MPD, X-ray diffractometer used to wide angle X-ray scans with the reflection mode which had a graphite monochromator and a $\mathrm{Cu}$ Ka radiation source at a scan rate of $0.5 \% \mathrm{~min}$ at room temperature. Both unmodified MMT and PP/MMT nano com wasnoted using, operated at $40 \mathrm{Kv}$ and $30 \mathrm{~mA}$. posites, XRD The samples were calculated from Bragg's equation by monitoring the diffraction angle $2 \mathrm{~h}$ from $2-10^{\circ}$ at a scanning rate of $0.5 \% \mathrm{~min}$.

\subsubsection{SEM and TEM}

The SEM images of the PP and PP/MMT nanocomposites, the fractured surfaces were coated thin layers of gold about 10 Ao. All SEM images were taken from JEOL, JSM $840 \mathrm{~A}$ scanning electron microscope with an accelerating of 10kv. The TEM images of unmodified MMT and PP/ MMT nanocomposites, the thin sections ranging from $70-100 \mathrm{~nm}$ in thickness were cut with a diamond knife using Reichert-Jung FCH ultra cryomicrotome cutter. The all TEM images were taken from a JEOL-EM-2000 FX Electron Microscope with $200 \mathrm{kV}$ accelerating voltage.

\subsubsection{Mechanical Testing}

The tensile samples were prepared according to the recommendation of ASTM D638. The tensile properties of PP/MMT nanocomposites at RT and $77 \mathrm{~K}$ were measured by a using universal testing machine (UTM) LR-100K (Lloyd Instrument Ltd U.K.) with a $10 \mathrm{kN}$ load cell, with a crosshead speed of $2 \mathrm{~mm} / \mathrm{min}$. The cryogenic temperature condition was achieved by dipping clamps and samples in a liquid nitrogen filled cryostat designed in our laboratory. The entire test was conducted while the sample and its loading fixture were submerged in liquid nitrogen. A schematic diagram of the loading fixture is shown in Figure 1. The flexural samples were prepared according to the recommendation of ASTM D-790. The flexural properties of PP/MMT nanocomposites at RT and $77 \mathrm{~K}$ were 


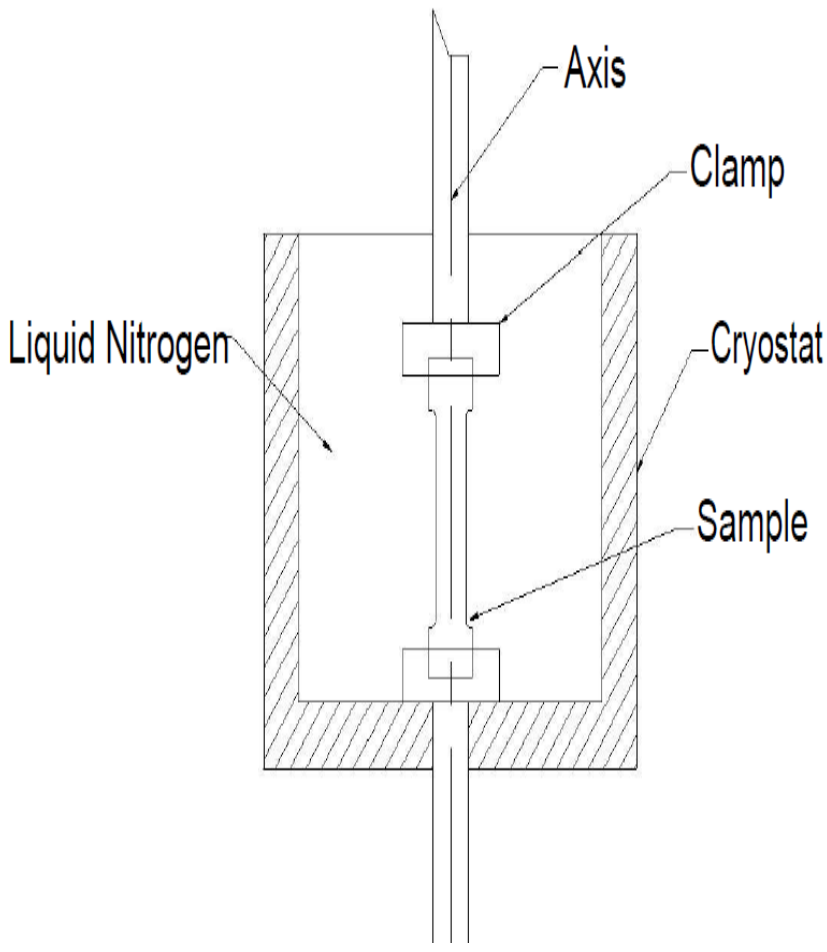

Figure 1. Schematic diagram of the fixture for cryogenic tensile testing.

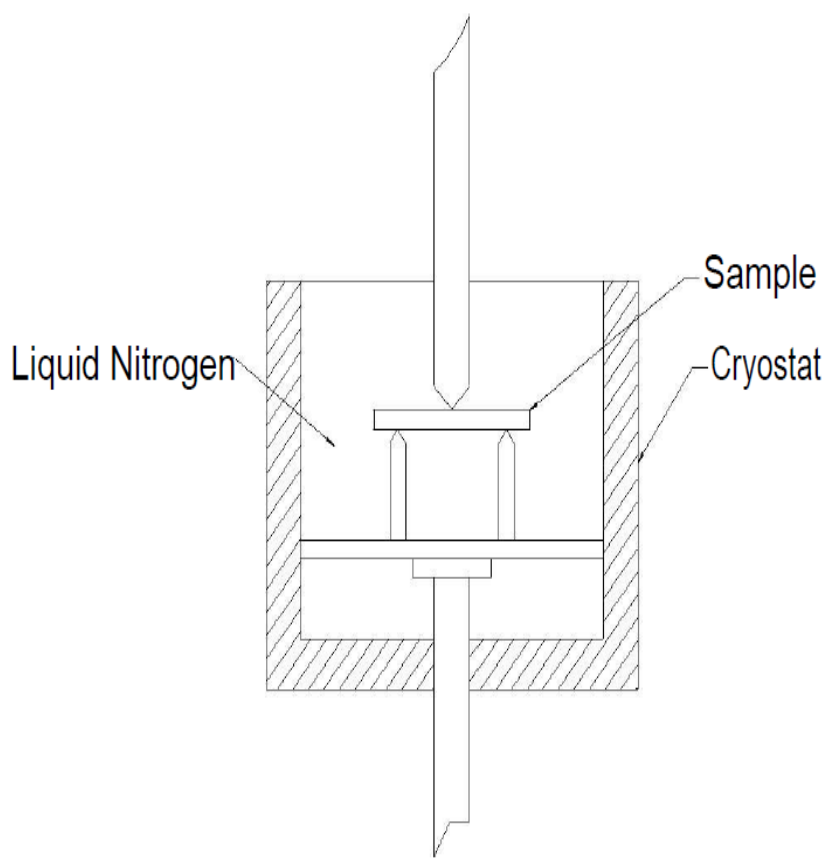

Figure 2. Schematic diagram of the fixture for cryogenic flexural testing. measured by a using Universal Testing Machine (UTM) LR-100K (Lloyd Instrument Ltd U.K.), with a cross head speed of $1.3 \mathrm{~mm} / \mathrm{min}$ and a span length of $50 \mathrm{~mm}$. The cryogenic temperature condition was achieved by dipping clamps and samples in a liquid nitrogen filled cryostat designed in our laboratory. The entire test was conducted while the sample and its loading fixture were submerged in liquid nitrogen. A schematic diagram of the loading fixture is shown in Figure 2. The notched impact strength was measured with a Reger Impact Tester according to ASTMD-256. Impact testing at $77 \mathrm{~K}$ was performed with the samples dipped in a liquid nitrogen filled cryostat for over $10 \mathrm{~min}$ and was completed in a couple of seconds after taking the specimens out from the cryostat. At least five specimens were tested for each composition. The temperature inside the samples was examined to have no obvious change after the samples were taken out from the cryostat for a few seconds using cryogenic thermocouples embedded inside the samples. Therefore, the temperature for the impact testing was approximately considered to be $77 \mathrm{~K}$.

\subsubsection{Dynamic Mechanical}

Viscoelastic properties such as storage modulus and loss modulus as a function of temperature were measured in a dynamic mechanical thermal analyzer (Netzsch DMA 242-C) with the temperature range from $200^{\circ}-150^{\circ} \mathrm{C}$. The frequency used was $1 \mathrm{~Hz}$ and the heating rate, $10^{\circ} \mathrm{C} / \mathrm{min}$. The specimen dimension was $60 \times 10 \mathrm{X} 3 \mathrm{~mm}$.

\section{Result and Discussion}

\subsection{X-ray Diffraction Analysis}

Figure 3 shows the XRD curve of unmodified MMT clay. In this Figure 3, the peak shifts from $2 \theta=6.98^{\circ}$, corresponding to basal d-spacing 12.6 Ao. XRD curves of $\mathrm{PP}$ and PP/MMT nanocomposites as shown in Figure 4 with the help of coupling agent the polymer intercalated between the intercalary spacing of layered silicates and the clay layers to move apart. The absence of peak showed the separation of clay layers and the formation of nanocomposites at $1 \mathrm{wt}$. \% to $5 \mathrm{wt}$. \% nanofiller reinforcement. This indication by TEM studies that intercalated structures have formed in $1 \mathrm{wt}$. \% and $3 \mathrm{wt}$. \% of nanofiller in PP/MMT nanocomposites. PP infused with 5 wt. \% of MMT hasexfoliated nanocomposites structures. 


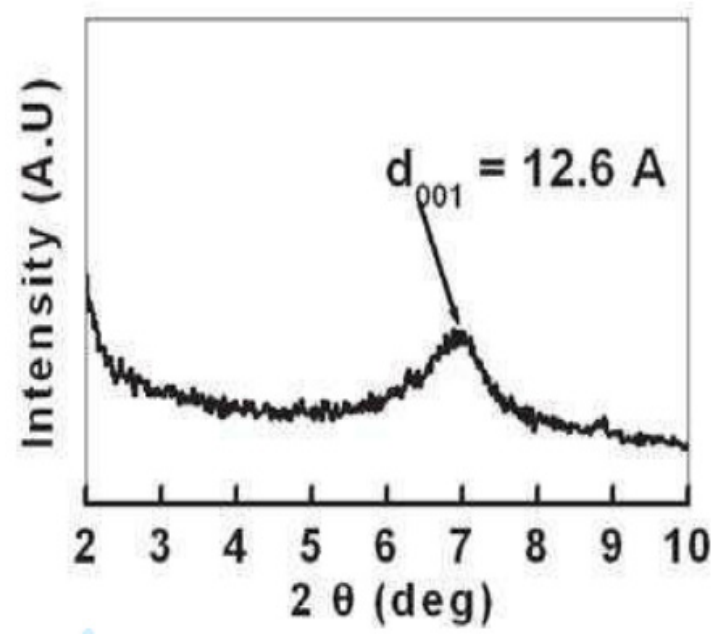

Figure 3. XRD curves of PP and PP/MMT composites.

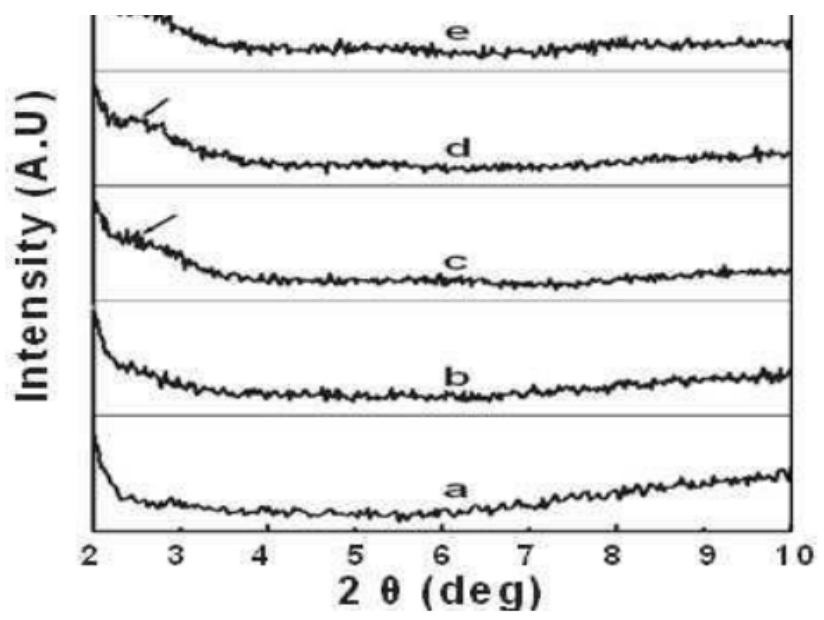

Figure 4. XRD curves of PP and PP/MMT composites

\subsection{TEM Analysis}

For the ease of comparison, TEM morphologies of the raw MMT and PP/MMT nanocomposites (1 wt \%, 3 $w t \%, 5 w t \%$ and $7 \mathrm{wt} \%)$ are presented in Figure $5 \mathrm{a}-\mathrm{e}$. The Figure 5a-e showed that the size of unmodified MMT clay particles is about $20 \mathrm{~nm}$ thick and 200-500 $\mathrm{nm}$ length. The Figure 5a-c showed the nanofiller has been further intercalated and exfoliated in the PP/MMT nanocomposites with the nanofiller reinforcement of 1 wt $\%, 3 \mathrm{wt} \%$ and $5 \mathrm{wt} \%$. From this result observed macromolecules of polymers formed the interlayer of the unmodified MMT during melt mixing process. The reason is that netlike macromolecules formed the interlayer of the MMT during the melting process. The d-spacing of unmodified MMT nanoclay is increased, which is consistent with the XRD curves (Figure 5c). However, some of the MMT actually consists of several layers, indicating that they were not fully exfoliated to the single layer. It is probably because they were not organically modified due to the charge of the pristine clay layer varying from layer to layer. When the content of MMT in composite was increased to $7 \mathrm{wt} \%$, the conglomerating probability of MMT and the quantity of non-exfoliated MMT inside PP matrix increased. Therefore, it can be seen in Figure $5 d$ that serious aggregations occurred everywhere at the MMT content of 7 wt $\%$. Similar results can also be drawn from Figure $5 \mathrm{~d}$.
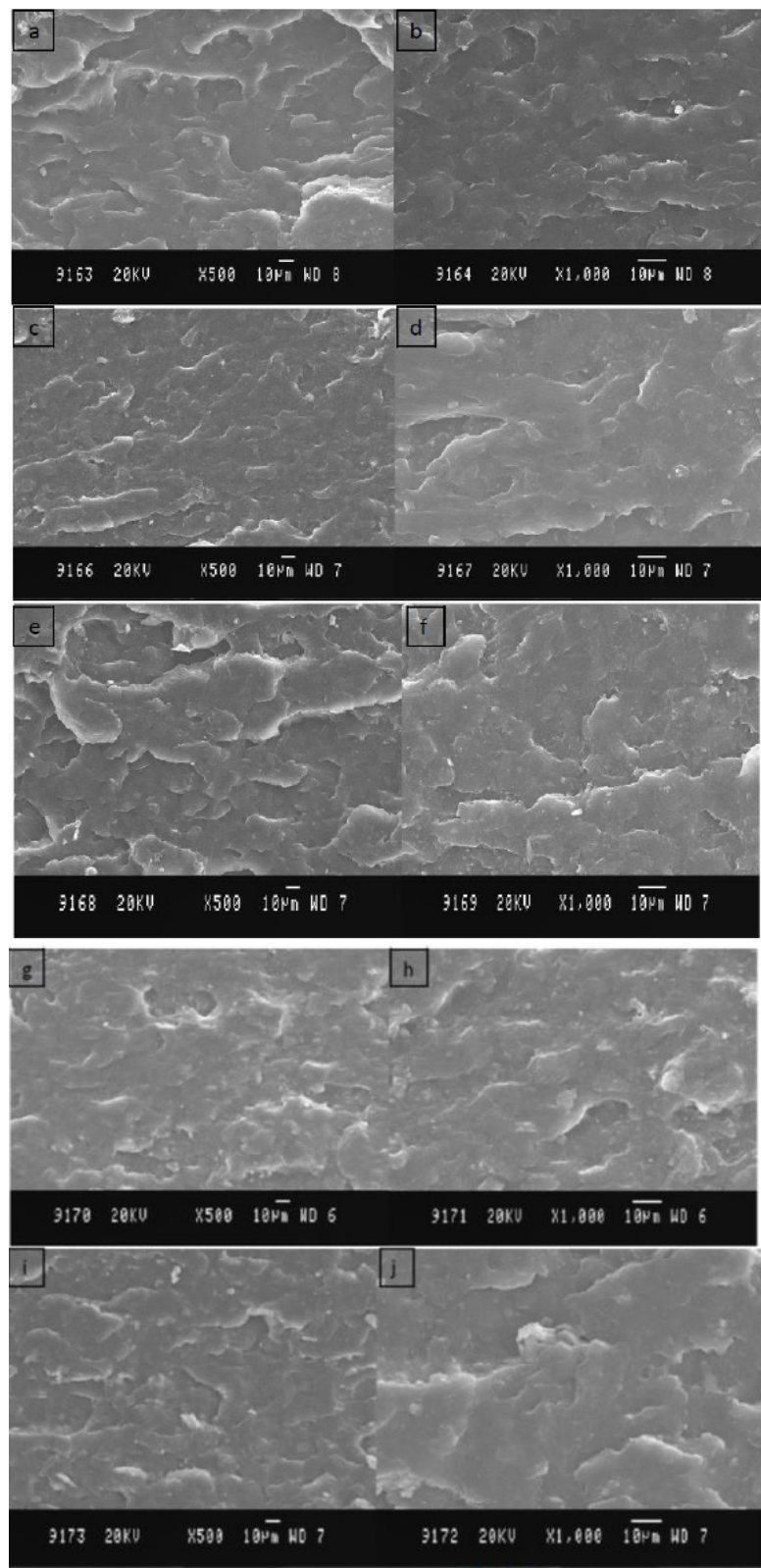

Figure 5. TEM micrograph of PP/MMT composites a)1 wt $\%$, b) 3 wt $\%$, c) 5 wt $\%$, d) 7 wt $\%$ and e)raw MMT. 


\subsection{Mechanical Properties}

\subsubsection{Tensile and Flexural Properties}

Figure 6 plots the tensile strength of the samples at RT and $77 \mathrm{~K}$. The unmodified MMT nanofiller were reinforced into the polymer at different weight percentage from zero to $7 \mathrm{wt} \%$. The results showed that nanofiller reinforcement into the polymer has marginal influence on the tensile strength of $\mathrm{PP} / \mathrm{MMT}$ nanocomposites. The nanofiller at $5 \mathrm{wt} \%$ increased the tensile by $3.1 \%$ and $13.2 \%$, at both RT and $77 \mathrm{~K}$, when compared with pure PP. Figure 7 plots the flexural strength of the samples at $\mathrm{RT}$ and $77 \mathrm{~K}$. The MMT nanoclay was reinforced into the polymer at different weight percentage from zero to $7 \mathrm{wt} \%$. The results showed that nanofiller reinforcement has significant influence on the flexural strength of PP/ MMT composites. As the content of MMT increases, the flexural strength at both $\mathrm{RT}$ and $77 \mathrm{~K}$ reaches maximum at the MMT content $3 \mathrm{wt} \%$, and increased by $11.5 \%$ and $21.2 \%$, respectively, when compared with those of pure PP samples. It can be seen from Figure $4 b-c$ that the intercalated and exfoliated MMT layers served as the short fasciculus inside the composite. The addition of short fasciculus to the PP matrix could reinforce the PP matrix and contributed to the increase of the tensile and flexural strength of the PP/MMT composite at the $5 \mathrm{wt} \%$ and 3 wt $\%$ MMT content. The tensile and flexural strength at $77 \mathrm{~K}$ was generally higher than that at RT at the same content of MMT. The strength of PP matrix becomes higher at $77 \mathrm{~K}$ and the interfacial adhesion becomes stronger at $77 \mathrm{~K}$ than at room temperature, leading to the higher strength. The thermal shrinkage caused by the big differences in the thermal expansion coefficients of PP and MMT would result in stronger interfacial adhesion strength between MMT and PP matrix at $77 \mathrm{~K}$ than at RT. On the other hand, the coefficient of thermal expansion (CTE) for MMT at RT was reported to be about $0.5 \times 10-5$ $\mathrm{K}-1$. And the CTE for MMT at cryogenic temperature should be somewhat lower than this value because thermal expansion coefficient is closely related to thermal oscillation while intensity of thermal oscillation becomes weaker as temperature decreases, leading to a lower CTE. As a consequence, the 'short fasciculus' were clamped more tightly by the PP matrix at $77 \mathrm{~K}$ than at RT, resulting in higher tensile and flexural strength at $77 \mathrm{~K}$ than that at RT. The tensile strength at RT and $77 \mathrm{~K}$ decreased when the MMT content was further increased to $7 \mathrm{wt} \%$ and flexural strength at RT and $77 \mathrm{~K}$ decreased when the
MMT content was further increased to $5 \mathrm{wt} \%$ and $7 \mathrm{wt} \%$. This might be mainly attributed to the fact that the percentage of aggregated (namely non-exfoliated) MMT was higher at the higher MMT content (see Figure 3d). The micro-sized holes to be shown in Figure $8 \mathrm{~b}$ were indicative of pull-out of aggregated MMT particles. When the composite samples were tested under tensile loading, cracks might initiate at the aggregated MMT particles and propagated throughout the samples. Therefore, the tensile strength was lower at the higher MMT concentration.



Figure 6. Effect of MMT content on tensile strength of PP/ MMT composites at RT and $77 \mathrm{~K}$.

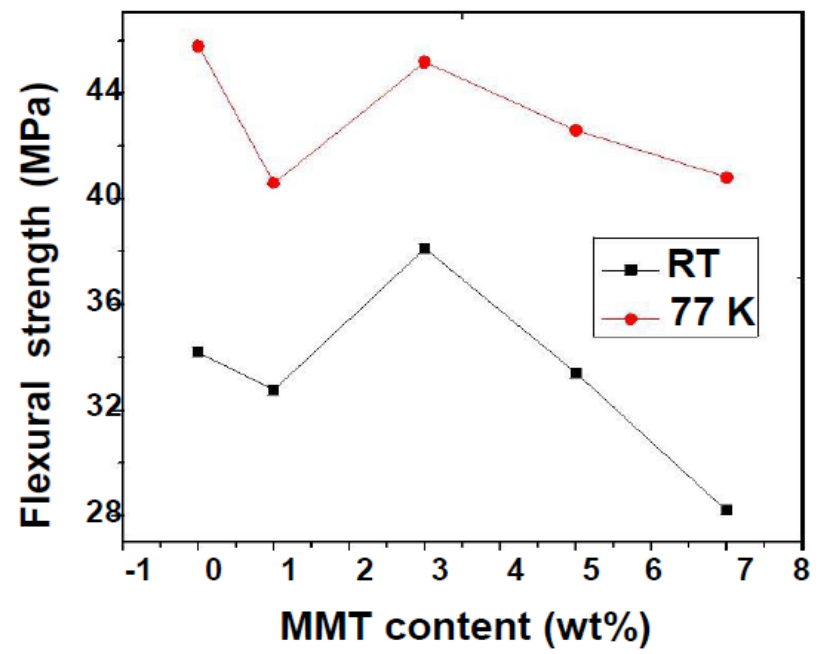

Figure 7. Effect of MMT content on flexural strength of PP/ MMT composites at RT and $77 \mathrm{~K}$. 
Figure 8 plots the tensile modulus of the nanocomposites at RT and $77 \mathrm{~K}$. The tensile modulus of PP and PP/ MMT nanocomposites at RT and $77 \mathrm{~K}$ was observed to increase almost linearly as the amount of nanofiller up to $5 \mathrm{wt} \%$ increased by $40.8 \%$ and $68.6 \%$, respectively, when compared with those of pure PP samples. Figure 9 plots the flexural modulus of the PP and PP/MMT .tively, when compared with those of pure PP samples. This is mainly because MMT has a higher modulus than PP matrix. Moreover, Figure 8 shows that the modulus at $77 \mathrm{~K}$ was much higher than that at RT at the same MMT content. This is because on the one hand, the modulus of the PP matrix at $77 \mathrm{~K}$ was higher than that at RT (see Figure 5 at zero MMT content) due to the tight arrangement of polymer molecules. On the other hand, any material would show higher modulus at lower temperature, so the modulus of MMT would also be higher at $77 \mathrm{~K}$ than at room temperature, contributing to the higher modulus of the composites at $77 \mathrm{~K}$ than at RT.

\subsubsection{Notched Impact Strength}

Figure 10 plots the impact strength of the nanocomposites at RT and $77 \mathrm{~K}$ as a function of MMT content. The notched impact strength at RT increased from $22.33 \mathrm{~J} / \mathrm{m}$ of the pure PP to $36.53 \mathrm{~J} / \mathrm{m}$ by the incorporation of MMT particles for the nanocomposite containing the $5 \mathrm{wt} \%$ MMT content while decreased for the composites containing the $7 \mathrm{wt} \% \mathrm{MMT}$ content.

Toughness improvement of nanocomposites can be attained when MMT in pure PP can resist the propagation of cracks at the $5 \mathrm{wt} \%$ MMT content at RT as indicated by the increase of notched impact strength. The rougher surfaces of the nanocomposites in Figure $5 \mathrm{c}-\mathrm{d}$ than those of pure PP matrix in Figure $5 \mathrm{a}-\mathrm{b}$ are indicative of the improvement in toughness. Moreover, the notched impact strength at $77 \mathrm{~K}$ was shown to be lower than that at RT except for the pure PP matrix. The sharp decrease of the notched impact strength at $77 \mathrm{~K}$ for the cases of all $\mathrm{PP} / \mathrm{MMT}$ nanocomposites may be caused by the thermal stresses due to the different contractive coefficients between the organic and inorganic phases when cooled down to $77 \mathrm{~K}$. The increase of the notched impact strength at $77 \mathrm{~K}$ for the pure PP matrix may be attributed to tight arrangement of molecules and no different contractive coefficients in the homogeneous phase.

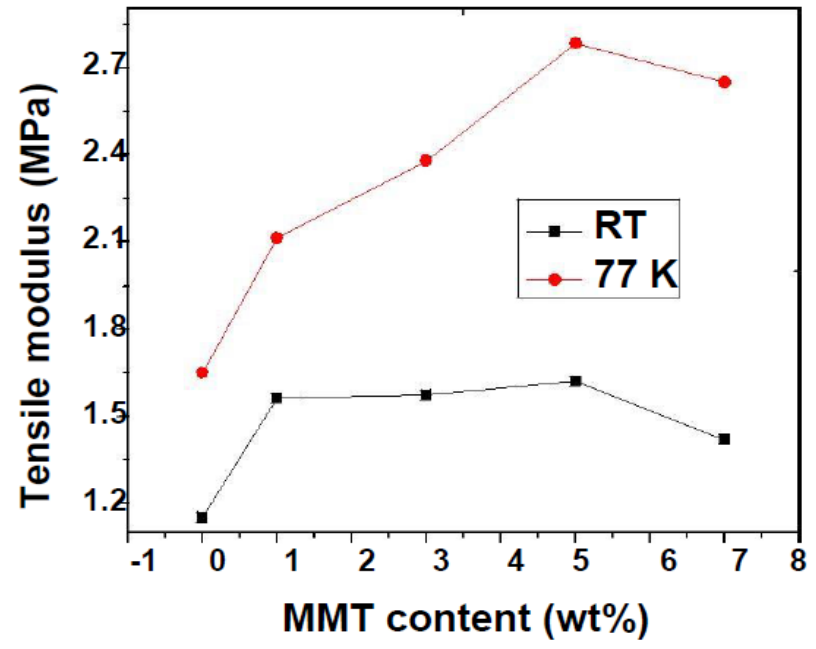

Figure 8. Effect of MMT content on tensile modulus of PP/ MMT composites at RT and $77 \mathrm{~K}$.

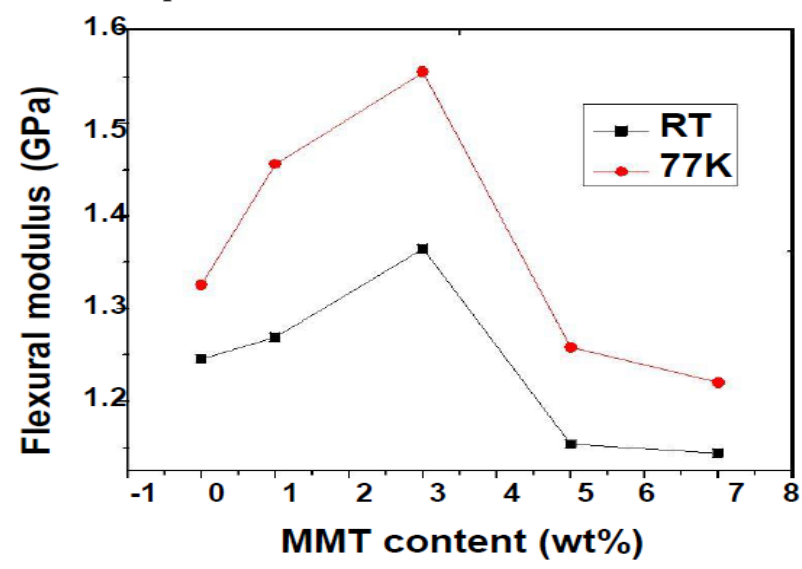

Figure 9. Effect of MMT content on flexural modulus of $\mathrm{PP} / \mathrm{MMT}$ composites at RT and $77 \mathrm{~K}$.

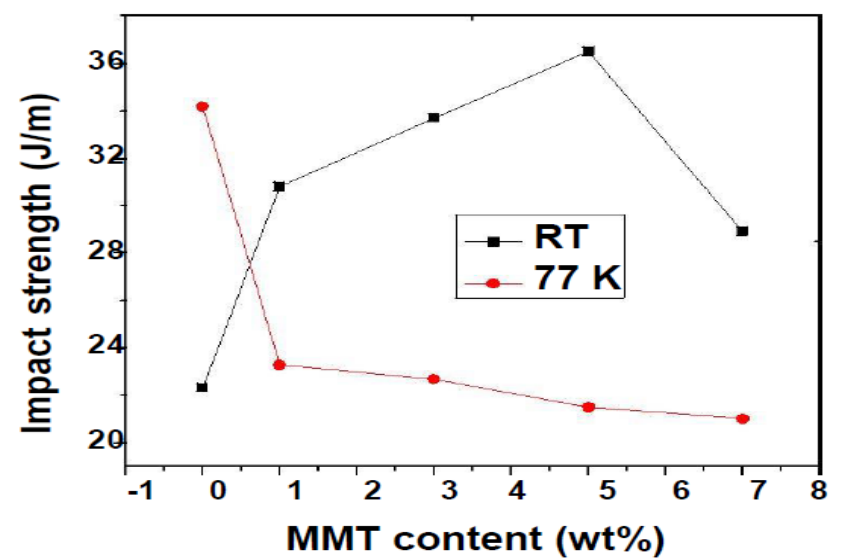

Figure 10. Effect of MMT content on impact strength of $\mathrm{PP} / \mathrm{MMT}$ composites at RT and $77 \mathrm{~K}$. 


\subsection{SEM Analysis}

The fracture surfaces of the nanocomposites were observed using SEM. Figure 11a-j displays some representative SEM images of the fracture surfaces of the notched impact samples at RT and $77 \mathrm{~K}$. Figure 11 shows that the surfaces of the pure PP samples were smooth and featureless, representing brittle failure of homogenous materials. As shown in the SEM images for the $\mathrm{PP} / \mathrm{MMT}$ nanocomposite samples with the $1 \mathrm{wt} \%, 3$ wt $\%, 5 \mathrm{wt} \%$ and $7 \mathrm{wt} \%$ MMT content, the fracture surfaces were significantly different from those of pure PP matrix samples. The fracture surfaces were broken into small and rough fracture pieces, contributing to improvement of the toughness of the nanocomposites. However, the improved toughness by the rough fracture surfaces for the cases of and $1 \mathrm{wt} \%, 3 \mathrm{wt} \%$ and $5 \mathrm{wt} \%$ would be overwhelmed by the effect of aggregation of Figure 11 shows that the fracture surfaces of samples at MMT particles since micro cracks would relatively easily initiate at the micro sized aggregated MMT particles, resulting in a reduced macroscopic toughness as shown in Figure 10. On the other hand, $77 \mathrm{~K}$ were smoother than those at RT at the same content of MMT except for the pure PP matrix, which represents more brittle fracture of the nanocomposites at $77 \mathrm{~K}$.

\subsection{Dynamic Mechanical Analysis}

Figure 12 plots the storage modulus of the $\mathrm{PP}$ and $\mathrm{PP} /$ MMT nanocomposites at RT and $77 \mathrm{~K}$. The results showed that unmodified MMT clay nanofiller have marginal influence on the storage modulus of PP/MMT respectively, when compared with those of pure PP samples. Figure 13 plots the loss modulus of the samples at RT and $77 \mathrm{~K}$ as a function of weight percentage of MMT from zero to $7 \mathrm{wt} \%$. The results show that MMT content has no influence on the loss modulus of PP/MMT composites. As the content of MMT increases, the loss modulus at both RT and $77 \mathrm{~K}$ reaches minimum at the MMT content up to $5 \mathrm{wt} \%$, and decreased by $3.1 \%$ and $13.2 \%$, respectively, when compared with those of pure PP samples.

\section{Conclusion}

The cryogenic mechanical properties and dynamic mechanical analysis of $\mathrm{PP} / \mathrm{MMT}$ nanocomposites prepared by adding the MMT nano filler content to pure PP matrix have been studied. XRD and TEM results showed that MMT can be exfoliated at the $5 \mathrm{wt} \%$ MMT content.
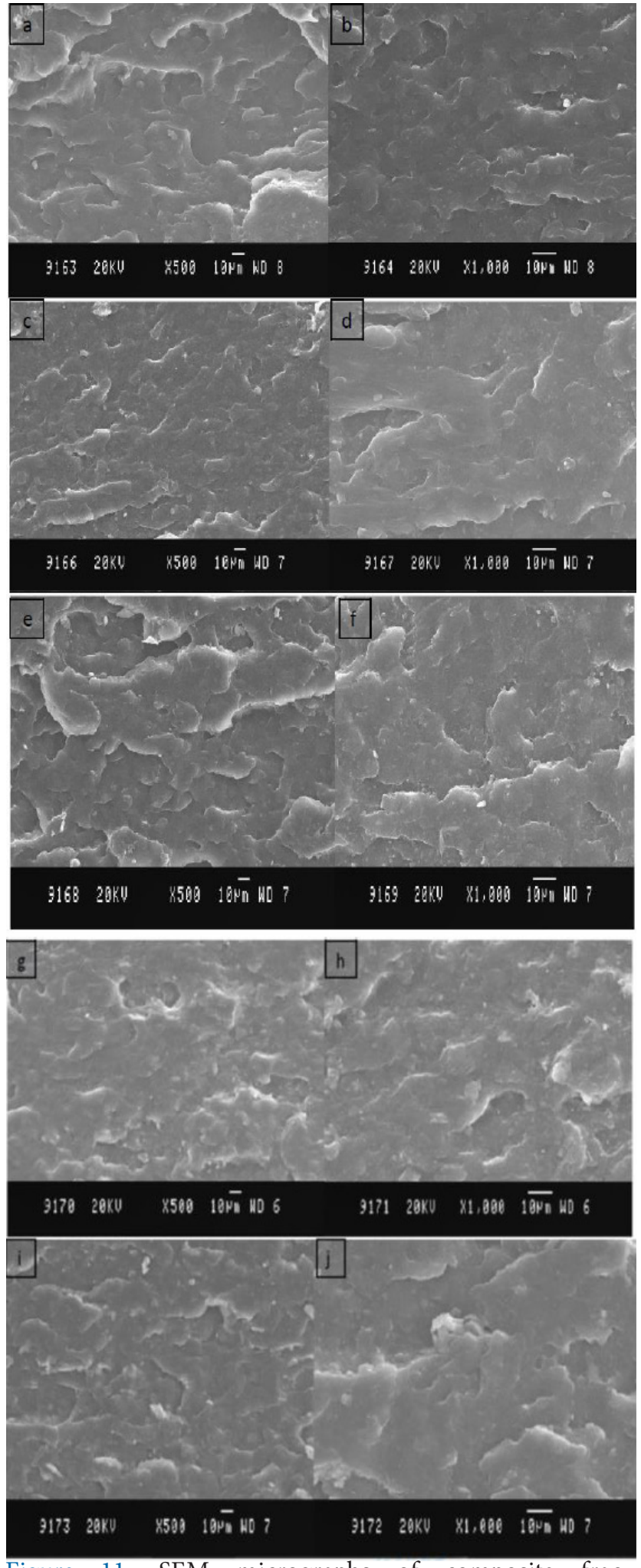

Figure 11. SEM micrographs of composite fracture surfaces for (a) pure PP, RT; (b) pure PP $77 \mathrm{~K}$; (c) $1 \mathrm{wt} \% \mathrm{RT}$;(d) $1 \mathrm{wt} \% 77 \mathrm{~K}$;(e)3 wt\% RT;(f)3 wt\% $77 \mathrm{~K}$;(g) 5 wt\% RT;(h)5 wt\% $77 \mathrm{~K}$;(i)7 wt\% RT and (j)7 wt\% $77 \mathrm{~K}$. 


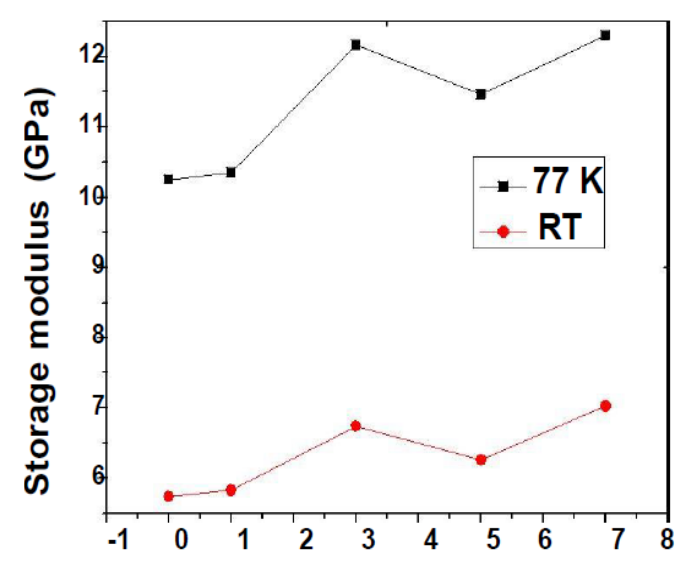

Figure 12. Eftect of MM'l content on storage modulus of $\mathrm{PP} / \mathrm{MMT}$ composites at RT and $77 \mathrm{~K}$.

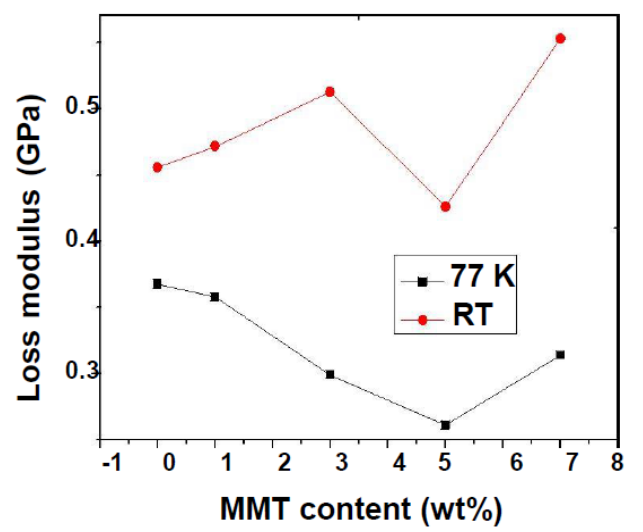

Figure 13. Effect of MMT content on loss modulus of PP/ MMT composites at RT and $77 \mathrm{~K}$.

The tensile modulus of nanocomposites at both RT and $77 \mathrm{~K}$ increased almost linearly with the increase of MMT content. Moreover, both the tensile strength and tensile modulus at $77 \mathrm{~K}$ were much higher than those at RT. strength of PP/MMT nanocomposites at both RT and $77 \mathrm{~K}$ reached the maximum at the $5 \mathrm{wt} \% \mathrm{M}$ MT content, increased by $3.1 \%$ and $13.2 \%$, respectively, as compared with those of pure PP sample. The mechanical results showed that the tensile The notched impact strength at RT increased from
$22.33 \mathrm{~J} / \mathrm{m}$ for the pure PP matrix to $36.53 \mathrm{~J} / \mathrm{m}$ for the nanocomposite with the 5 wt\% MMT content. It was also observed that the notched impact strength at $77 \mathrm{~K}$ was lower than that at RT except for the pure $\mathrm{PP}$ matrix. The storage modulus of PP/MMT nanocomposites at both $\mathrm{RT}$ and $77 \mathrm{~K}$ reaches maximum at the MMT content up to $3 \mathrm{wt} \%$, and the loss modulus of PP/MMT nanocomposites at both RT and $77 \mathrm{~K}$ reaches minimum at the MMT content up to $5 \mathrm{wt} \%$.

\section{Refernces}

1. Yun SI, Gadd GE, Latella BA, Lo V, Russell AR, Holden PJ. Polymer Bull. 2008; 61:267-75.

2. Weon JI, Sue HJ. J Mater Sci. 2006; 41:2291-300.

3. Wang Y, Chen FB, Li YC, Wu KC. Composites: Part B. 2004; 35:111-24.

4. Muksing N, Nithitanakul M, Grady BP, Magaraphan R. Polymer Test. 2008; 27:470-9.

5. Zeng QH, Yu AB, Lu GQM, Paul DR. Journal of Nanoscience and Nanotechnology. 2005; 5:1574-92.

6. Guz IA, Rushchitsky JJ. Int Appl Mech. 2004; 40:785-93.

7. Zhao Y, Huang H. Polymer Test. 2008; 27:129-34.

8. Nayak SK, Mohanty S, Samal SK. Polymer-Plast Tech Eng. 2009; 48:976-88.

9. Modesti M, Lorenzetti A, Bon D, Besco S. Polymer. 2005; 46:10237-45.

10. Zhou Y, Rangari V, Mahfuz H, Jeelani S, Mallick P. Mater Sci Eng A. 2005; 402:109-17.

11. Wang G, Chen XY, Huang R, Zhang L. J Mater Sci Lett. 2002; 21:985-6.

12. Sreekala MS, Lehmann B, Friedrich K, Rong MZ. Int J

Polym Mater. 2006; 55:577-94.

13. Ruan WH, Zhang MQ, Rong MZ, Friedrich K. J Mater Sci. 2004; 39:3475-8.

14. Garica M, Vliet GV, Jain S, Schrauwen BAG, Sarkissov A, van Zyl WE, Boukamp B. Rev Adv Mater Sci. 2004; 6:169-75. 15. Bao SP, Tjong SC. Mater Sci Eng A. 2008; 485:508-16.

16. Yang J, Lin Y, Wang J, Lai M, Li J, Liu J, Tong X, Cheng H. J Appl Polymer Sci. 2005; 98:1087-91. 